\title{
Henoch schonlein purpura in pregnancy: a lesser known phenomenon
}

\section{Salil Bindu Chakrabarti, Maureen Prativa Tigga*, Jayanta Ray, Amulya Debbarma}

Department of Obstetrics \& Gynaecology, Agartala Government Medical College \& GB Pant Hospital, Agartala, Tripura, India

Received: 05 June 2015

Accepted: 09 July 2015

\author{
*Correspondence: \\ Dr. Maureen Tigga, \\ E-mail: maureentigga@gmail.com
}

Copyright: (C) the author(s), publisher and licensee Medip Academy. This is an open-access article distributed under the terms of the Creative Commons Attribution Non-Commercial License, which permits unrestricted non-commercial use, distribution, and reproduction in any medium, provided the original work is properly cited.

\section{ABSTRACT}

Henoch Schonlein Purpura is a rare disease and its occurrence during pregnancy is exceptional. Very little information is found in the literature regarding this topic and only handful of case reports are available to throw light upon the same. Presented here is a case of a 30 year old primigravida with pre-existent disease with successful fetomaternal outcome subsequently.

Keywords: Henoch Schonlein Purpura, Pregnancy

\section{INTRODUCTION}

Henoch-Schönlein purpura (HSP) is an acute immunoglobulin A (IgA) mediated disease characterized by generalized vasculitis involving the small vessels of the skin, gastrointestinal (GI) tract, kidneys, joints and rarely, lungs and the central nervous system (CNS) ${ }^{1}$ It manifests as rash, especially involving the legs which is the hallmark of the disease; abdominal pain, vomiting \& bloody stools; joint pain involving typically the knees and ankles and subcutaneous edema. ${ }^{2}$ The diagnosis of HSP is clinical and no specific laboratory test is available to assess for markers of the disease. HSP is more commonly reported in children and the peak incidence is between 2 and 5 years of age. Studies show that the incidence in 2 to 14 year old population is 14 cases out of 100000 per year. ${ }^{3}$ HSP in pregnancy is an extremely rare occurrence and to the best of our knowledge as per the available literature, about 20 cases have been reported so far. We are reporting another case of a primigravida who was a diagnosed case of HSP and presented to our antenatal clinic at 32 weeks of gestation.

\section{CASE REPORT}

A 30 year old primigravida reported to our OPD at 32 weeks of gestation for her antenatal booking. She had no complaints except she revealed to us that she was diagnosed with HSP 2 years back. In the past her symptoms included pruritic rashes in the lower limb along with arthralgia; and an episode of severe epigastric pain accompanied with vomiting for which she was admitted and investigated in a tertiary care hospital. Her investigations included skin biopsy from leg which showed small vessel vasculitis with lymphocytic infiltration and extravasted RBCs. Her complete blood count, renal function test, coagulation profile (Prothrombin time, INR \& aPTT) was normal. Tests to exclude autoimmune disorders like Anti-phospholipid antibody, AntiDs DNA antibody, cANCA, pANCA, Antinuclear antibody were negative. She was administered steroid (Prednisolone) with gradual tapering of dose for three months following which her symptoms subsided markedly (except few rashes in her lower limbs). Her present pregnancy was spontaneous conception which occurred one and a half year after remission of disease. On examination patient was of an average built, her pulse rate was $80 / \mathrm{min}$ and blood pressure was $120 / 70 \mathrm{~mm}$ of $\mathrm{Hg}$. Her lower limbs showed few scars of previous pruritic lesions and also a scar at the biopsy site. Fresh purpuric patches were found confined to her thighs and groin and had developed in the past 2 weeks. Per abdominal examination suggested a single live foetus corresponding to 32 weeks of gestation 
with breech presentation which was confirmed by ultrasonography (USG). The patient was advised for a fresh set of investigations especially her renal function test along with urinary protein, coagulation profile, platelet count and USG Doppler. All her investigations were within normal range. She was administered injection betamethasone for foetal lung maturation which also facilitated diminution in the severity of purpuric patches. At 36 weeks 5 days of gestation, patient complained of decreased foetal movement. USG with biophysical profile was done which showed Manning Score: $8 / 10$ (foetal body movement was less). Patient underwent caesarean section and delivered a healthy baby of $3.6 \mathrm{~kg}$. There were no intraoperative complications and her postoperative period was uneventful. Patient was discharged on 5th day of her surgery. The biopsies taken from the placenta and the navel string were reported normal with no evidence of vasculitis.

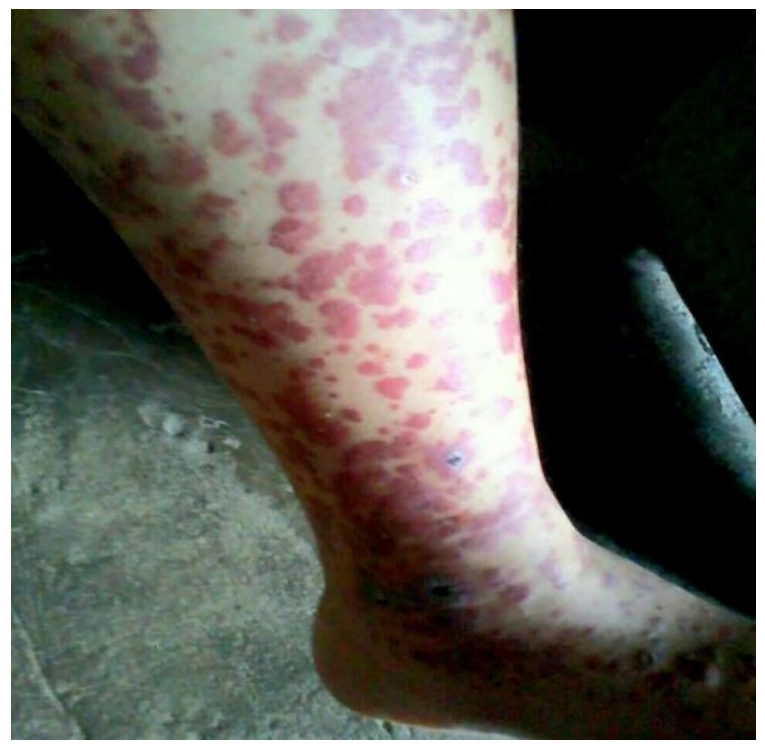

Figure 1: Cutaneous manifestation of henoch schonlein purpura in the patient before pregnancy.

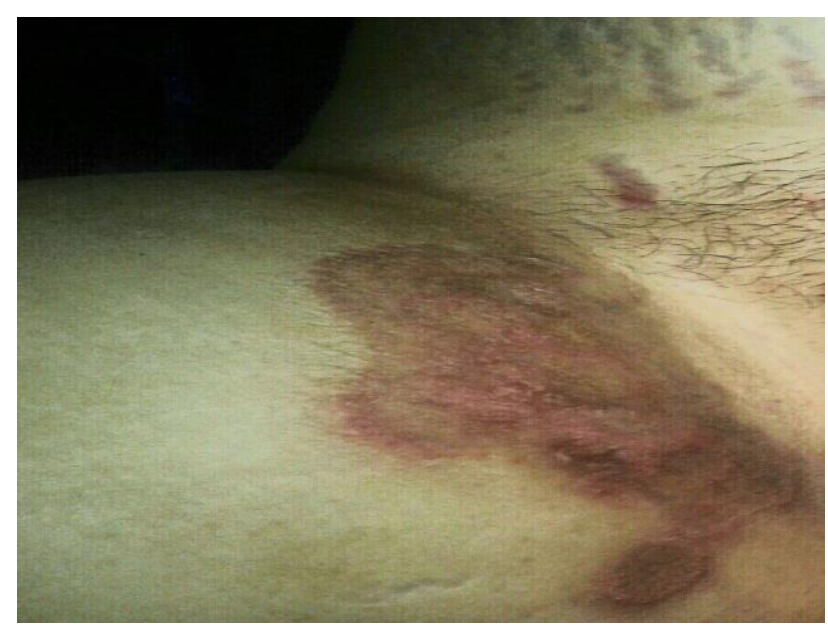

Figure 2: Cutaneous lesions in the patient during pregnancy.

\section{DISCUSSION}

HSP is a rare clinical entity manifesting as a result of IgA mediated small vessel vasculitis. The etiology of HSP is not clearly defined but is thought to be multifactorial, with genetic, environmental, and antigenic components. About $75 \%$ of patients have antecedent upper respiratory tract infection, pharyngeal or gastrointestinal infection. ${ }^{4}$ Multiple bacterial and viral infections have been attributed to the development of HSP, and cases have been reported after exposure to certain drugs and vaccinations.4Infections that precede the development of HSP include mononucleosis, group A streptococcal infection, hepatitis, sub-acute bacterial endocarditis, helicobacter pylori, salmonella \& shigella. ${ }^{5}$ Vaccinations that trigger the development of HSP include typhoid and paratyphoid A and B, measles and cholera. ${ }^{4}$ Environmental exposure to drugs (e.g., ampicillin, erythromycin, penicillin, quinidine, quinine etc.), certain food, horse serum \& insect bites have been implicated as a cause for HSP.

The prodrome of HSP includes headache anorexia \& fever followed by other symptoms like rash affecting predominantly the lower limbs; abdominal pain and vomiting; joint pain involving the knees and ankles; subcutaneous oedema and bloody stools. Arthralgias occur in up to two thirds of patients and arthritis is rarely observed. ${ }^{6}$ Gastrointestinal symptoms present as colicky pain, nausea, vomiting, diarrhoea, constipation and gastrointestinal bleeding. Endoscopic examination has demonstrated erosive lesions most commonly in the duodenum. $^{7}$ Acute episode of HSP may manifest neurological symptoms, headache being the most frequent while convulsions are rare. ${ }^{8}$ Renal involvement occurs in 25 to $50 \%$ of children. Proteinuria and microhaematuria are encountered as a result of glomerulonephritis. Glomerular changes include segmental and focal or diffuse mesangial IgA deposits. Although acute renal failure is rare, end-stage renal disease may develop as long as 20 years after diagnosis of HSP. ${ }^{9}$ Therefore careful clinical and laboratory supervision is required even after complete remission of skin lesions.

HSP in adults present with more extensive and chronic skin lesions ${ }^{10}$ and the severity and frequency of renal involvement is more in comparison to the paediatric counterpart. ${ }^{11}$ However, long term outcome of HSP seems to be equal in both age groups. ${ }^{11,12}$

Occurrence of HSP during pregnancy is very rare with no specific characteristics in terms of symptomatology. One may land up in diagnostic dilemma when renal, articular or gastrointestinal symptoms occur before the cutaneous manifestations. Many features of HSP like nephrotic syndrome (proteinuria), abdominal pain, headache and convulsions may masquerade as preeclampsia or eclampsia. 
Literature states various findings pertaining to HSP in pregnancy. Cummins et al. ${ }^{13}$ reported two patients developing new onset HSP at 16 \& 22 weeks gestation respectively while the third developing a recurrence of HSP at 12 weeks gestation after 19 years of remission thereby concluding that pregnancy may be a trigger for onset or recurrence for HSP in susceptible individuals. Feldman et al. ${ }^{14}$ reported a 35 year old primigravida at 31 weeks of gestation with history of purpura on the legs, epigastric pain and arthralgia. She was treated with lowdose oral corticosteroids which facilitated resolution of the skin lesions. Monica et al. ${ }^{15}$ presented two cases of HSP with pregnancy. In both the cases patients were treated with low-dose oral corticosteroids and had good fetomaternal outcome. Another case from Bangladesh, was reported by Praveen et al. ${ }^{16}$ where a 39 year old woman who was gravida 10 parity 1 with eight abortions developed cutaneous lesion at 24 weeks of gestation and was subsequently investigated and diagnosed as a case of HSP. She underwent caesarean section at 37 weeks delivering a healthy baby but due to adherent placenta causing intractable bleeding subsequent hysterectomy had to be performed.

The effect of pregnancy on pre-existent HSP needs further evaluation. As stated earlier, literature shows 4 cases with worsening of disease in two patients ${ }^{17,19}$ decreases in proteinuria in one patient ${ }^{15}$ and disparition of symptoms in one patient. ${ }^{20}$ In our patient there was an abrupt onset of fresh purpuric lesion at 30 weeks of gestation but there was no derangement in any of her laboratory tests or the foetal status. Corticosteroid administered to the patient facilitated both foetal lung maturation and alleviation of rashes. In our case both the maternal and foetal outcomes were good.

According to studies the obstetrical outcome is found to be favourable in the absence of renal involvement ${ }^{15,21-22}$ this was seen in our case too where the kidneys remained unaffected. The risk of $\operatorname{IgA}$ vasculitis in the foetus was reported negligible as this immunoglobulin cannot cross the placenta. Histopathological examination of the placenta in 2 cases showed no vasculitis ${ }^{14,15}$ which was similar to our finding.

Since HSP in pregnancy is a lesser found phenomenon, there is large scope for research about the disease in pregnancy, its impact on the fetomaternal outcome, and placental changes.

\section{CONCLUSION}

Due to its extreme rarity HSP in pregnancy needs to be further evaluated. The treatment protocols have not been specified due to little experience on this topic. Although corticosteroids and plasmapheresis have been used ${ }^{23}$, more evidence is required.
Funding: No funding sources

Conflict of interest: None declared

Ethical approval: Not required

\section{REFERENCES}

1. Jennette CJ, Milling DM, Falk RJ. Vasculitis affecting the skin. Arch Dermatol. 1994;130:899906.

2. Piette WW. What is Schönlein-Henoch purpura and why should we care? Arch Dermatol. 1997; 133:515518.

3. Nielsen HA. Epidemiology of Schönlein-Henoch purpura. Acta Pathol Scand. 1988,77:125-31.

4. Rigante D, Castellazzi L, Bosco A, Esposito S. Is there a crossroad between infections, genetics, and Henoch-Schönlein purpura? Autoimmune Rev. 2013;12(10):1016-21.

5. Hoshino C. Adult onset Schonlein-Henoch purpura associated with Helicobacter pylori infection. Intern Med. 2009; 10:847-51.

6. Cream JJ, Gumpel JM, Peachy RDG. SchoenleinHenoch purpura in the adult: a study of 77 adults with anaphylactoid or Schoenlein-Henoch purpura. Q J Med. 1970;39:461-84.

7. Vogt M, Maier M, Benz Z, Kaufmann V, Riemann JF. Schönlein-Henoch-Syndrom mit schwerer Abdominalbeteiligung beim Erwachsenen. Dtsch Med Wschr. 1996;121:871-5.

8. JR, Storm K. Neurological manifestations of Schönlein-Henoch purpura. Acta Paediatr Scand. 1992;0:339-42.

9. Goldstein AR, White RHR, Akuse R, Chantler C. Long term follow-up of childhood Henoch-Schönlein nephritis. Lancet. 1992;339:280-2.

10. Michel BA, Hunder GG, Bloch DA, Calabrese LH. Hypersensitivity vasculitis and Henoch-Schönlein purpura: a comparison between the 2 disorders. J Rheumatol. 1992;19:721-8.

11. Blanco R, Martinez-Taboada VM, RodriguezValverde V, Garcia-Fuentes M, Gonzalez-Gay MA. Henoch-Schönlein purpura in adulthood and Childhood. Arthritis Rheum. 1997;40:859-64.

12. Tancrede-Bohin E, Ochonisky S, Vignon-Pennamen MD, FlageuI B, Morel P, Rybojad M. SchönleinHenoch purpura in adult patients. Arch Dermatol. 1997;133:438-42.

13. Cummins DL, Mimouni D, Rencic A, Kouba DJ, Nousari C. Henoch-Schönlein purpura in pregnancy. Br J Dermatol. 2003;149(6):1282-5.

14. Feldmann R, Rieger W, Sator PG, Gschnait F, Breier F. Schönlein Henoch purpura during pregnancy with successful outcome for mother and newborn. BMC Dermatology. 2002;2:1.

15. Ray M, Posen GA. Hench Schonlein purpura in pregnancy. Can Med Asso J. 1985;132(12):1385-6.

16. Praveen T, Begum F. Henoch Schonlein Purpura, a rare disease in pregnancy. Bangladesh $\mathrm{J}$ Obstet Gynecol. 2008;23(2):73-7. 
17. Plauche WC. Henoch-Schönlein (anaphylactoid) nephropathy in pregnancy. Obstet Gynecol. 1980;56:515-7.

18. Kalmantis K, Daskalakis G, Iavazzo C, Vranos A, Mesogitis S, Antsaklis A. Henoch-Schonlein purpura in pregnancy. J Obstet Gynaecol. 2008;28(4):403-5.

19. Joseph G, Holtman JS, Kosfeld RE, Blodgett WA, Liu YK. Pregnancy in Henoch-Schönlein purpura.Am J Obstet Gynecol. 1987;157:911-2.

20. Merill J, Lahita RG. Henoch-Schönlein purpura remitting in pregnancy and during sex steroid therapy. Br J Rheumatol. 1994;33:586-8.

21. Koizumi M, Hagino D, Fukuyama C, Abe K, Inoue $\mathrm{K}$, Arai Y, et al. Schönlein-Henoch purpura during pregnancy: Case report and review of the literature. $\mathbf{J}$ Obstet Gynaecol Res. 2004;30(1):37-41.
22. Muszytowski M, Ruszkiewicz-Fołda M. A case of acute renal failure in pregnancy complicated by Henoch-Schoenlein purpura requiring hemodialysis therapy. Ginekol Pol. 1996;67(1):42-4.

23. Ekoukou D, Karaoui B, Bazin C. Rheumatoid purpura (or Schoenlein-Henoch syndrome) and pregnancy. Review of the literature and a case report. J Gynecol Obstet Biol Reprod. 1997;26(2):197-201.

Cite this article as: Chakrabarti SC, Tigga MP, Ray J, Debbarma A. Henoch Schonlein Purpura in pregnancy: a lesser known phenomenon. Int J Reprod Contracept Obstet Gynecol 2015;4:1227-30. 